\title{
Women Professionals Need To Move towards Positive Health:
}

\section{A Review}

\author{
Mrs. K. Sumathi ${ }^{1}$, Dr. N. Prathiba ${ }^{2}$
}

\section{ABSTRACT}

Women professionals are the distinct category of working women with high educational achievement, aspirations, goals and career development motivation. To fulfil such desires and aspirations they have to face various demands and expectations which may cause a set of issues. Thus it is essential for them to have positive mental health. Mental Health is the determinant factor for the personal effectiveness, success happiness and effective participation. It influences the individual's activities, behaviour, happiness and performance. The present study takes up with the objective to know the mental health status and the factors for mental health among the women professionals through research studies by various researchers.

Keywords: Mental Health, Women Professionals, Marital adjustment, Work Family conflict and psychological well being

It is an established fact that the women's contribution is enormous for the economic growth of the nation through their wide contribution of work force in every sphere. The women professionals are the distinct category of working women with high aspirations and achievement motivation due to the gift of the urbanization and modernization. Today they are with sufficient skills and knowledge and try to prove their efficiency in every field which motivates them to have high career achievement. On the other hand they need to get ready to face more expectations to sustain and to fulfill their strong desire. In their work place they are expected to be ambitious, competitive, dynamic, professionally committed with sound knowledge and update their skills and also to be competent enough. Besides in the family and in the society they need to perform various roles. Hence the women professionals have to play multiple roles in their day to day life and at the same time they are not ready to give up or compromise any of these roles.

\footnotetext{
${ }^{1}$ Ph.D. Research Scholar, Department of Social Work, Karpagam Academy of Higher Education, Coimbatore, Tamilnadu, India

${ }^{2}$ Associate Professor, Department of Social Work, Karpagam Academy of Higher Education,Coimbatore, Tamilnadu, India

*Responding Author Received: February 21, 2017; Revision Received: March 23, 2017; Accepted: March 29, 2017

(C) 2017 Sumathi k, Prathiba N; licensee IJIP. This is an Open Access Research distributed under the terms of the Creative Commons Attribution License (www.creativecommons.org/licenses/by/2.0), which permits unrestricted use, distribution, and reproduction in any Medium, provided the original work is properly cited.
} 


\section{Women Professionals Need To Move towards Positive Health: A Review}

Thus it is the huge challenge for them to balance all without damaging their physical and psychological health, so it is important for them to have positive mental health.

\section{Mental Health}

Mental health describes either a level of cognitive or emotional well-being. It is an individual's ability to enjoy life and procure a balance between the life activities and effort to achieve psychological resilience. The concept of mental health includes the subjective wellbeing without any mental illness. There are many concepts to define mental health. According to WHO, Mental health is not just the absence of mental illness. It is defined as a state of well-being in which every individual realizes his or her own potential, can cope with the normal stresses of life, can work productively and fruitfully, and is able to make a contribution to his or her community. (WHO, 2007)

It is a combined outcome of five types of health-physical, emotional, moral, spiritual and social, considered as an important aspect of the total health of a person because it causes and effects other types of health (Gill \& Kaur, 2005).

Mental health refers to the full and harmonious functioning of the total personality as well as to the bio-socio-psychological and spiritual well being (Dandapani, 2000).

Jagdish and Srivastava (1983) define mental health as a person's ability to make positive selfevaluation, to perceive the reality, to integrate the personality, autonomy, group-oriented attitudes and environmental mastery.

According to Smith and Segal (2011), "People who are emotionally and mentally healthy have the tools for coping with difficult situations and maintaining a positive outlook which also remain focused, flexible, and creative in bad times as well as good”.

According to the expert committee of WHO on Mental health defines, the mental health as "the capacity of an individual to form harmonious relationships with others and to participate in or contribute constructively to change in the Social environment."

Bhatia (1982) considers mental health as the ability to balance feelings, desires, ambitions and ideals in one's daily living. It means the ability to face and accept the realities of life.

Mental Health is feeling about ourselves, and about others and also the way people meet the demands of life.

\section{REVIEWS ON MENTAL HEALTH AMONG WOMEN PROFESSIONALS}

The technological development and modernization have brought many changes in the lives of women today. These changes insist them to perform various roles in order to go along with this

(C) The International Journal of Indian Psychology, ISSN 2348-5396 (e)| ISSN: 2349-3429 (p) | 10 


\section{Women Professionals Need To Move towards Positive Health: A Review}

current world. This new demands and expected role changes force them to equip themselves through increasing their awareness, skills, knowledge and to avail the resources and opportunities effectively with their participation. Hence it is essential for them to have more adjustment in the family and in their profession as well.

Dr. Shikha Goel, Dr. Darshan Kaur Narang and Dr. Kavita Koradia have conducted their study (2013) on "The marital adjustment and mental health in middle aged couples (40-55 years) from Delhi, India” with the sample comprised of 100 working couples $(n=200)$ which are bank employees and doctors, within the age range of 40-55 years. They stated that the bank employees, autonomy are positively correlated with family adjustment, positive self evaluation, financial adjustment and social adjustment; whereas integration of personality is found correlated with role distribution. On the other side, perception of reality is negatively correlated with the recreational adjustment and role distribution. A significant interactive affect of job and age on marital adjustment, mental health is found. Not much difference is there in the marital adjustment and mental health of the bank employees and doctors. It is assumed that the bank employees and doctors are very ambitious; career oriented and spends more time outside the family. So, they have to make adjustment within the family responsibilities and work roles. This can have an impact on their marital adjustment and mental health. Females are having better marital adjustment than males. If working females play dual roles, they are over burdened but still they try to make adjustments in family and are satisfied and cool under all the circumstances. They participate in family matters, cooperate more and make themselves available when ever required. They try to seek recreation and satisfaction out of the successful management.

Srimathi, N. L., and Kiran Kumar, S. K. (2010) have conducted their study about "Psychological Well being of Employed Women across Different Organisations". They examine the level of the psychological well being among the working women in different professions with the sample of 325 women working in different organizations - industries, hospitals, banks, educational institutions and in call centers/BPOs. The results of the study reveal that women employees working in industries have least psychological well being in all the sub factors and total psychological well being scores, followed by women working in health organizations. Women employees working in banks have medium level of psychological well being scores. Women teachers have highest total psychological well being scores and also in the entire sub factors of psychological well being.

Mishra Garima and Dr. Kiran U. V.(2014) have carried out a study about the "Impact of Marital Status on Mental Health of Working Women" in Lucknow. The 90 working women from various institutions and sectors are the samples of their study. It is revealed that the married working women have more difficulty in managing their work and family as compared to unmarried working women. It is also observed that married working women have stressful job 
experience because they had to make balance between their family and job. In the other case, unmarried working women have less stressful experience because they focus only on their job. The results obtain on the consequences of stress reveals significant differences among the married and unmarried working women. Married working women have to face a lot of problem like difficulty in their work, taking care of things at home, loss of interest in things, feeling emotionally numb, avoid talking about stressful situation and feeling cut off from others. Whereas, in the case of unmarried working women, consequence of stress is very optimum. Due to job stress married working women are highly affected by physical problems, they were easily startled and they do not want to remember any type of stressful experience from the past. This study intends to find out the impact of marital status on the mental health of working women. The result of the study shows that the significant effect indicates the consequence of stress on mental health of married and unmarried working women. Married women receive high mean score than unmarried working women and the result states that the unmarried working women are less affected by job stress. The study also reveals a significant effect of the emotional problem among the working women. Unmarried working women have better emotional health than the married working women. Thus the research reveals that the marital status has a significant impact on the mental health of working women.

Jieun Song, Nadine F.Marks and Gyoung-Hae Han (2007) have studied about "Work, family, work-family spillover and mental health among working adults - A comparison of data from national surveys in Korea and the U.S”. Guided by bioecological systems theory, this study aims to examine the associations between the work micro systems characteristics (working hours, decision latitude, work pressure), family micro systems characteristics (marital status, parental status), work-family mesosystem factors (positive and negative work family spillover) and mental health (depressive symptoms, positive effect, psychological well-being) among the working women and men. The moderating effects of the cultural context (Korea vs. U.S.) are also evaluated. OLS regression models are estimated using the data from 1,260 working women (Korea: 463, U.S.: 797) and 1,659 working men (Korea: 795, U.S.: 864) aged 30-59 who participated in nationally representative survey studies of middle aged adults in Korea (MIDKO) and the U.S. (MIDUS).Results indicate that: (1) The associations between the work micro system factors and mental health of working adults are somewhat different across the countries. More working hours is associated with the better mental health of women and men regardless of the country context. More work pressure is associated with the women's poorer mental health, particularly among the U.S. women. More decision latitude is associated with the better mental health, particularly among Korean men. (2) There are significant differences between the countries in associations between the family micro system factors and mental health. Being married is associated with the better mental health among Korean women and men compared to the U.S. women and men. Having children is also associated with the poorer mental health among Korean women and men compared to the U.S. women and men. (3) There are significant differences across the cultural context in the strength of associations between the work-family 
spillover and mental health for some mental health dimensions. Positive work to family spillover is associated with the better mental health among the working adults, except for Korean women who has experienced more depressive symptoms with the presence of more positive work to family spillover. Negative work to family spillover is linked to poorer mental health of working adults, particularly among the U.S. women and men compared to their Korean counterparts. Positive family to work spillover is associated with the better mental health of women and men, particularly among the U.S. women and men compared to their Korean peers. Negative family to work spillover is associated with the poorer mental health of working women, particularly among the U.S. women compared to Korean women. Negative family to work spillover is also associated with poorer mental health of working men, and this association is stronger among Korean men in contrast to the U.S. men. Overall, findings suggest work, family, and work-family spillover are significantly associated with the various dimensions of mental health of the working adults, sometimes contingent on the cultural context, supporting the assumptions of the bioecological systems theory.

Soumya Sharma and R.K. Sokhi (2016) conduct their research study on "Psychological wellbeing amongst women professionals in different spheres of work-life”. They examine the role of profession in determining psychological well being amongst the working women with the sample of 180 working women aged 25-55 years and employed in three different working sectors viz. Public (60), Private (60) and Teaching (60) is selected. The aim of the present research is to study the relationship between professional groups (Public, Private and Teaching) and psychological well-being, and if any significant difference emerges in the levels of psychological well-being across the three groups. According to the findings of the study, teaching professionals exhibit the highest psychological well-being level followed by public sector and lastly private sector professionals. It is also found that teaching women professionals have significant higher level of autonomy and personal growth as compared to other two professional groups and private women professionals have significant higher levels of purpose in life as compared to other two professional groups. From the findings of the present research the public women professionals have found to be high on the sub-dimension of the environmental mastery.

These findings can be attributed to the fact that public sector professionals have fixed working hours, flexibility and a sense of job security as compared to private sector professionals who are working under the constant pressure in order to meet the deadlines and are not provided enough flexibility and job security which could lead to an overall low psychological well-being.

Mustafa Koyuncu,Ronald J. Burke and Jacob Wolpin (2012) conduct their research study on "Work-family conflict, satisfactions and psychological well-being among women managers and professionals in Turkey" with the sample size of 143 women, most working in the public sector, using anonymously completed questionnaires. About half are married and about half have children. They examine the correlation and consequences of work family conflict among 
managerial and professional women working in Istanbul, Turkey. They have measured work family conflict (WFC), both work interfering with family and family interfering with work. The findings of the study reveal that the respondents indicate relatively low levels of WFC. Levels of work interfering with family and family interfering with work are significantly and positively correlated. Hierarchical regression analyses, controlling for both personal demographic and work situation characteristics, show that the WFC generally predicted both work and psychological well-being outcomes, work interfering with family being a consistently stronger predictor of these than the family interfering with work. Managerial and professional women report higher levels of work to family work interference than family to work interference (H1), scores on work to family interference are significantly and positively correlated with scores on family to work interference. The respondents (H2), managerial and professional women reporting higher levels of work to family interference would report lower levels of work outcomes and psychological well-being (H3), and work to family interference would have stronger effects of work and wellbeing outcomes than the family to work interference (H4). Contrary to H4, family to work interference has no relationship with either work or well-being outcomes. The families with children in Turkey have to access effective child care, often from other family members (e.g. parents, siblings, relatives) or from relatively inexpensive child-care workers. Thus, guild about leaving one's children at home while working is likely to be low among these Turkish women, perhaps lowering both family-work conflict and WFC. Nevertheless, the findings indicate that the higher levels of work to family interference are associated with lower levels of psychological health and less favorable work outcomes.

\section{CONCLUSION}

There are many research studies on working women and their problems due to their multiple roles and the consequences behind these role demands by various researchers. These studies covered the various areas like work life balance, marital adjustment, family adjustment, role stress, occupational stress and the health issues. An important gap to be noticed here is that the positive sides of health especially mental health with different dimensions has to be studied. It is very vital today, because the women's career and profession has accepted but still the roles and responsibilities are not shared by anybody. Besides the women are getting ready to overcome their hurdles without giving up any of their roles. Thus their positive health must be strengthened by themselves to avoid the health issues and more in depth researches are needed in this area.

\section{Acknowledgments}

The author appreciates all those who participated in the study and helped to facilitate the research process.

Conflict of Interests: The author declared no conflict of interests. 


\section{REFERENCES}

Bhatia, B. D., 1982, Mental health in education. Advanced educational psychology, Sterling publishers pvt. Ltd., 121-125.

Dandapani, S. (2000). A Text Book of Advanced Psychology. Anmol Publication Pvt. Ltd. New Delhi, India, pp. 510.

Dr. Shikha Goel, Dr. Darshan Kaur Narang \& Dr. Kavita Koradia(2013) Marital adjustment and Mental Health among Bank employees and Doctors during middle age (40-55 Years) in Delhi. International Journal of Scientific and Research Publications, Volume 3, Issue 1, 1 ISSN 2250-3153

Gill, S. and Kaur, G. (2005). Moral judgement, intelligence and parental behaviour as correlates of mental health. Malwa J Edu, 1(1): 56-62.

Jagdish and Srivastava, A.K. (1983). Manual for Mental Health Inventory (MHI) Manovaigyanik Parikchhan Santhan, Varanasi, India.

Mental Health. (2017). Wikipedia. Retrieved 13 March 2017, from http://www.en.wikipedia.org/wiki/Mental_healthon 01/09/2012

Mishra Garima \& Dr. Kiran U. V. (2014) Impact of Marital Status on Mental Health of Working Women. Journal of Medical Science and Clinical Research (JMSCR), Volume 2, Issue10, Page 2594-2605

Mustafa Koyuncu Ronald J. Burke Jacob Wolpin, (2012),"Work-family conflict, satisfactions and psychological well-being among women managers and professionals in Turkey", Gender in Management: An International Journal, Vol. 27 Iss 3 pp. 202 - 213

Work Experiences, Satisfactions and Psychological Well-being among Women Managers and Professionals in Turkey. (2017). ResearchGate. Retrieved 15 March 2017, from https://www.researchgate.net/publication/241613808

Impact of Marital Status on Mental Health of Working Women. (2017). ResearchGate. Retrieved 3 March 2017, from https://www.researchgate.net/publication/267506019

Smith, M., Segal, R., \& Segal, J. (2011). Improving Emotional Health. Health guide.

Song, J., Marks, N.F., \& Han, G. (2007). Work, family, work-family spillover and mental health among working adults: Comparison of Korean and U.S. National surveys. Family and Culture, 19(2), 61-92.

Soumya Sharma,R.K. Sokhi (June 2016) Psychological Well-Being Amongst Women Professionals in Different Spheres of Work-Life .International Journal of Education and Psychological Research (IJEPR) Volume 5, Issue 2, Page-57-61

Srimathi, N. L., Kiran Kumar, S. K. (2010),Psychological Well being of Employed Women across Different Organisations. Journal of the Indian Academy of Applied Psychology, 36(1), 89-95.

World Health Report (2001). Mental Health: New Understanding, New Hope. World Health Organization, 2001.

How to cite this article: Sumathi k, Prathiba N (2017), Women Professionals Need To Move towards Positive Health: A Review, International Journal of Indian Psychology, Volume 4, Issue 2, No. 95, ISSN:2348-5396 (e), ISSN:2349-3429 (p), DIP:18.01.162/20170402, ISBN:9781-365-84231-3 